\title{
Pandemias y su efecto en el turismo: lecciones del pasado y nuevos retos
}

\section{Pandemics and their impact on tourism: Lessons from the past and challenges for the future}

\author{
Ema Carmen Julca Meza* \\ Escuela Profesional de Turismo y Hotelería, \\ Universidad de San Martín de Porres, Perú
}

\section{Resumen}

La pandemia a causa de la COVID-19 está colocando al mundo en una crisis generalizada. Sin tratamiento ni vacuna disponible, y debido a su elevado nivel de contagio, la única estrategia posible es la contención; es decir, restringir el desplazamiento humano y establecer una cuarentena en casa y cierre de empresas y, más aún, actividades turísticas y de recreación. Medidas que han generado enormes disrupciones económicas en el sector turismo. En el presente trabajo, se explora la intervención de los viajes y el turismo en la transmisión de infecciones y su impacto en las enfermedades epidémicas; además, cómo la pandemia está afectando al turismo en el Perú y qué organismo es clave para la recuperación durante y después de la pandemia.

Palabras clave: COVID-19, turismo, pandemias, Perú.

\begin{abstract}
COVID-19 pandemic is challenging the world. With no treatment or vaccine available, and due to the high transmissibility rate of the virus, the only possible strategy is to contain the pandemic by imposing travel restrictions, issuing stay-at-home orders, closing businesses, and mainly
\end{abstract}

Este es un artículo Open Access bajo la licencia Creative Commons Atribución-NoComercial-Compartirlgual 4.0 
forbidding tourism and recreational activities. These measures have caused huge economic disruption in the tourism sector. This research work examines the position of travelling and tourism in the transmission of infections, and their impact in epidemics. Furthermore, the study discusses how COVID-19 is affecting tourism in Peru, and what organism has a key role for its recovery during and after the pandemic.

Keywords: COVID-19, tourism, pandemic, Peru.

\section{Introducción}

La pandemia por COVID-19 está cobrando millones de vidas a nivel mundial y dejando efectos en la salud física y emocional de las personas. Como consecuencia de la inestabilidad y restricciones, más de 200 países se ven perjudicados severamente en su economía, uno de los sectores más golpeados es el turismo, ya que la economía del turismo se basa en las relaciones económicas que surgen de la producción, distribución y consumo de productos y servicios turísticos (Moragues, 2006). Por ser el desplazamiento de las personas la columna vertebral de esta economía, todo el sistema colapsa.

En el presente trabajo se explora la intervención de los viajes y el turismo en la transmisión de infecciones y su impacto en las enfermedades epidémicas. Un antecedente cercano es el ocasionado por la influenza del 2009 que dejó lecciones para considerarlas en esta pandemia por coronavirus y sus grandes estragos económicos, especialmente en el sector turismo. En la actualidad, toda actividad turística se encuentra frenada y aún es incierta la vuelta a la normalidad. Lo ocurrido durante la influenza afectó muchísimo y la recuperación del sector turístico requirió también grandes esfuerzos; sin embargo, en el caso de la COVID-19 los retos son mayores, prevenir la propagación de la enfermedad depende de la creación y aplicación de la vacuna que sigue en proceso. Por lo tanto, es necesario contar con propuestas reales y efectivas para restablecer la actividad turística en el mundo y, por ende, en el Perú. 


\section{Rol de los viajes en la transmisión de las infecciones}

El rol de los viajes y los desplazamientos es descrito como una de las principales causas de contagio y propagación de enfermedades (Wilder-Smith y Freedman, 2003). Los viajes internacionales y el desarrollo tecnológico de la industria aeronáutica han transformado la magnitud y movilidad de las poblaciones, transportándonos y poniéndonos en contacto como nunca antes visto (Tapper, 2006). El gran desarrollo y aumento del transporte aéreo, en particular los viajes internacionales, se han considerado como un factor importante para la propagación de enfermedades contagiosas por vía aérea, donde los viajeros son vías de transmisión de infecciones (Mangili y Gendreau, 2005). Si bien el viajero puede adquirir la infección en su país de origen, también puede ser infectado en el destino y propagarlo en adelante si visita otros países.

En casos de pandemia, las autoridades gubernamentales de todos los países, adoptan estrategias específicas para los brotes epidémicos restringiendo los viajes. Estas restricciones no han sido estudiadas en profundidad, pero son una manera frecuente y eficaz de reducir la propagación de infecciones epidémicas (Camitz y Liljeros, 2006). Un claro ejemplo de esto es cuando en el 2003 la OMS, solicitó a la población de viajeros internacionales que posterguen sus salidas cuando el síndrome respiratorio agudo grave (SARS por sus siglas en inglés) produjo un brote; a raíz de ello, se tomó medidas extremas en los aeropuertos, entradas marítimas y de carreteras. También, de manera más drástica, se negó la entrada a hoteles y cruceros, se detuvo entrega de visas para viajeros provenientes de ciudades o países de riesgo o afectados (McKercher y Chon, 2004); asimismo, estas medidas y la posibilidad de quedarse a la deriva fuera de su país han tenido un impacto psicológico significativo que ha repercutido en la industria del turismo a nivel mundial (Wilder-Smith y Freedman, 2003).

\section{El impacto de las enfermedades epidémicas en los viajes y el turismo}

El brote de enfermedades epidémicas como la COVID-19 puede crear ansiedad en la población debido al desconocimiento de su manejo y la incertidumbre sobre su evolución; además de la facilidad y rapidez en la transmisión en ciertos entornos. Esta situación ha generado un impacto 
considerable en la economía de las naciones ya que está demostrado el efecto sobre la dinámica del turismo (Dombey, 2004; Mason-Jones et al., 2016; McKercher y Chon, 2004). Las restricciones en las diversas actividades empresariales y turísticas, necesarias para evitar la propagación del virus, interrumpen el flujo de visitantes, tanto en países desarrollados como en desarrollo, afectando económicamente el turismo global.

Por ejemplo, brotes epidémicos anteriores han impactado directamente en la industria de la aviación, ya que el número de pasajeros aéreos puede caer hasta en un $80 \%$ y las tasas de ocupación hotelera pueden caer a menos del $10 \%$ en algunos casos. Asimismo, los espacios recreativos como tiendas, restaurantes, supermercados, centros comerciales, clubes, bares, parques y calles se ven casi vacíos. Aunque la imagen desfavorable acerca de los destinos turísticos puede basarse en gran medida a los hechos de las enfermedades infecciosas, cabe mencionar que también pueden provenir de la amenaza percibida de la enfermedad, más que de su peligro real. En tales casos, los medios de comunicación y el gobierno juegan un papel crucial, en la medida que publiquen notas alarmistas y sensacionalistas con respecto a los efectos de la enfermedad (McKercher y Chon, 2004).

En tal sentido, el impacto negativo sobre el turismo puede ser más una consecuencia de las reacciones del gobierno a la amenaza percibida de epidemias. En las crisis internacionales, la reacción exagerada y la falta de coordinación afectan el flujo turístico. Un ejemplo, es la pandemia en 2009 de influenza H1N1, la cual fue asumida de diversas maneras por la población. En el Perú, la prensa adoptó una actitud más bien ambigua y contradictoria, que combinaba titulares sensacionalistas con editoriales y artículos de especialistas que, por el contrario, minimizaban los temores frente a la nueva enfermedad.

\section{0: COVID-19 en el Perú y sus consecuencias en el sector turismo}

En marzo de 2020 el turismo se paralizó en todo el mundo a causa de una pandemia por COVID-19, suponiendo un desafío mayor para las marcas, las empresas y los destinos. El escenario en turismo reporta pérdidas incalculables debido al cierre de fronteras y cancelación de vuelos. A consecuencia que el virus se ha regado por decenas de países, también se estima que el flujo 
turístico mundial caiga entre 1\% y 3\% respecto a 2019 (Castro, 2019). La industria de viajes de Estados Unidos se encuentra entre las más afectadas; la US Travel Association proyecta una pérdida de 4.6 millones de empleos hasta mayo, una cifra que probablemente irá en aumento.

La disminución del turismo es una razón importante para la pérdida de empleos en Estados como Nevada, donde los casinos y los hoteles gigantes de Las Vegas se han oscurecido. El impacto en los viajes es seis o siete veces mayor que los ataques del 11 de septiembre, dice Roger Dow, presidente y CEO de la Asociación de Viajes de EE. UU. Esta asociación fomenta los viajes hacia y dentro del país y representa una industria que genera $\$ 2.6$ billones en economía y soporta 15.8 millones de empleos en los Estados Unidos.

Gran parte de la industria del turismo construyó su estrategia financiera en torno a un futuro sin problemas, planeando cielos azules eternos: fronteras abiertas; alta demanda turística, una industria de $\$ 8$ billones que desafía los altibajos del mercado. Con base en las restricciones de viaje y una recesión mundial esperada, IATA estima que los ingresos de la industria del transporte aéreo global podrían caer $\$ 252000$ millones, 44\% por debajo de los números de 2019.

En el Perú, según fuentes del Ministerio de Comercio Exterior y Turismo. (MINCETUR, 2020), con hoteles, museos, restaurantes y atractivos turísticos cerrados, el sector está padeciendo un duro golpe. Según explicó la ex viceministra de Turismo, Mara Seminario, dicho sector «mueve mucho la microeconomía», por lo que tiene impacto en la población que trabaja y vive de esa actividad y que no necesariamente es parte de una mediana o gran empresa. «Mucha gente vive del turismo. No solamente agencias de viajes, grandes hoteles o líneas aéreas, sino también taxistas, mozos, artesanos o guías turísticos. Es gente que todos los días recibía dinero de su actividad dentro del sector turismo», declaró para este informe (como se citó en MINCETUR, 2020).

En 2019, Perú recibió un total de 2.2 millones de turistas internacionales, dato de un fuerte incremento con respecto al año anterior, y se preveía que se incrementaría para 2020 (MINCETUR, 2020). Por ser un destino turístico de excelencia, ese año, se recibió alrededor de 4.4 millones de turistas en Lima, 
Cuzco, Tacna, Puno y Arequipa; siendo el turismo del PBI nacional el 3.6\%. Con la aparición de la epidemia, la disminución del flujo de turistas provenientes de Europa y Norteamérica, supone un severo golpe para el sector (MINCETUR, 2020).

Actualmente, el gobierno peruano ha puesto en marcha un fondo de 30000 millones de soles para microempresarios del sector turismo, de forma que puedan acceder a créditos que les permitan pagar a sus trabajadores y proveedores, y así evitar que la cadena de pagos se rompa. Carlos Villena Lezcano, director de la Escuela de Turismo, Hotelería y Gastronomía de la Universidad Ricardo Palma, ejemplificó la dinámica económica dentro de este sector:

Una agencia de viaje con nueve trabajadores en Pueblo Libre se dedica a la venta de tickets aéreos nacionales e internacionales. También podría vender paquetes de turismo para determinada región, por decir Cusco. En Cusco reciben la orden de compra de Lima con sus 15 turistas. Esta agencia en Cusco, a su vez, se interrelaciona con otras microempresas que proveen servicios: guías, transportistas, restaurantes, hoteles o tiendas artesanales. El sector turismo requiere y necesita de otras actividades. (como se citó en Barrenechea, 2020, párr. 8)

Villena Lezcano también prevé que en lo que queda del año el sector turismo se sostendrá básicamente por la demanda interna. «Creo que las autoridades del Mincetur son conscientes que lo que queda es darle un enorme esfuerzo al desarrollo de turismo interno hasta diciembre», indicó. El turismo internacional aún «tomará tiempo» en recuperarse (como se citó en Barrenechea, 2020).

Desde la Cámara Nacional de Turismo, su presidente Carlos Canales ha pedido al Poder Ejecutivo tomar medidas para apoyar de manera diferenciada a este sector, el más golpeado por la pandemia. Su propuesta es que el Estado subsidie el $80 \%$ de los salarios de los empleados formales del sector turismo, que son alrededor de 1450000 personas. Afirma que la crisis afectará a más de 800000 empleos, provocando una pérdida económica de cerca de 200000 millones de dólares, y donde los más afectados serán las PYMES, pequeños 
negocios de emprendedores rurales comunitarios en turismo que son los más afectados. El programa de las Naciones Unidas para el Desarrollo, en conjunto con el gobierno peruano, laboran para fortalecer a este grupo de emprendedores, basados en las promociones de PromPeru (como se citó en Barrenechea, 2020).

Con la pandemia urge el restablecimiento de los espacios turísticos y la confianza en las actividades de oferta. El papel de PromPeru es crucial para reactivar, sobre todo, los viajes internos mientras se recuperan los viajes internacionales. Para lograr el objetivo se han puesto en marcha diversos protocolos de seguridad en hoteles, restaurantes y atracciones turísticas con el fin de reactivar esta economía.

\section{Conclusiones}

- Los viajes y desplazamientos se encuentran entre las principales causas de propagación de enfermedades.

- Durante la pandemia, para prevenir el contagio, una de las primeras medidas adoptadas es la inmovilización humana.

- Los principales países afectados son aquellos cuyas economías se basan, en un gran porcentaje, en actividades turísticas.

- En el Perú, el incremento económico proyectado en el sector turismo para el año 2020 se ha visto severamente afectado por la pandemia del coronavirus.

- El gobierno del Perú ha establecido un plan de apoyo económico, para que los microempresarios del sector turismo puedan pagar a sus trabajadores y proveedores.

- El programa de las Naciones Unidas para el Desarrollo, en conjunto con el gobierno peruano, basados en la promoción y reactivación de PromPeru, laboran para fortalecer a los emprendedores del sector turismo.

- El papel de PromPeru es crucial para reactivar, sobre todo, los viajes internos mientras se recuperan los viajes internacionales. 


\section{Referencias}

Barrenechea, M. (2020). Coronavirus y el golpe al turismo: ¿Cómo impacta la crisis en el empleo? https:/l rpp.pe/peru/actualidad/coronavirus-y-el-golpe-al-turismo-como-impacta-la-crisis-en-el-empleo-noticia1257442

Camitz, M. y Liljeros, F. (2006). The effect of travel restrictions on the spread of a moderately contagious disease. BMC Medicine, 4(1), 32. https://doi.org/10.1186/1741-7015-4-32

Castro, J. C. (2019, 20 de diciembre). Turismo cerrará 2019 con el peor crecimiento en los últimos 17 años. Turiweb, Noticias de Turismo y Viajes. https://www.turiweb.pe/turismo-cerrara-el-2019-con-peor-crecimientode-los-ultimos-17-anos/

Dombey, O. (2004). The effects of SARS on the Chinese tourism industry. Journal of Vacation Marketing, 10(1), 410. https://doi.org/10.1177/135676670301000101

Mangili, A. y Gendreau, M. A. (2005). Transmission of infectious diseases during commercial air travel. The Lancet, 365(9463), 989-996. https://doi.org/10.1016/S0140-6736(05)71089-8

Mason-Jones, A. J. L. C., Sinclair, D., Mathews, C., Kagee, A., Hillman, A. y Lombard, C. (2016). Cochrane Library Cochrane Database of Systematic Reviews School-based interventions for preventing HIV, sexually transmitted infections, and pregnancy in adolescents (Review). https://doi.org/10.1002/14651858.CD006417.pub3

McKercher, B. y Chon, K. (2004). The over-reaction to SARS and the collapse of Asian tourism. Annals of Tourism Research, 31(3), 716-719. https://doi.org/10.1016/j.annals.2003.11.002

Ministerio de Comercio Exterior y Turismo (MINCETUR). (2020, 23 de marzo). COVID-19: El sector turismo no está solo. https://www.gob.pe/institucion/mincetur/noticias/109877-covid-19-el-sector-turismo-no-esta-solo

Moragues, D. (2006). Turismo, Cultura y Desarrollo. Organización de Estados Iberoamericanos para la Educación, la Ciencia y la Cultura. https://www.oei.es/historico/cultura/turismodmoragues.htm

Tapper, M. L. (2006). Emerging viral diseases and infectious disease risks. Haemophilia, 12(s1), 3-7. https://doi.org/ 10.1111/j.1365-2516.2006.01194.x

Wilder-Smith, A. y Freedman, D. O. (2003). Confronting the New Challenge in Travel Medicine: SARS. Journal of Travel Medicine, 10(5), 257-258. https://doi.org/10.2310/7060.2003.2669 